\title{
How to Green the red Dragon: A Start-ups' Little Helper for Sustainable Development in China
}

\author{
Henk J. Steinz, ${ }^{1}$ Frank J. Van Rijnsoever ${ }^{1 * *}$ and Frans Nauta ${ }^{2}$ \\ ${ }^{1}$ Utrecht University - Innovation Studies, Copernicus Institute of Sustainable Development, \\ Utrecht, The Netherlands \\ ${ }^{2}$ Climate-KIC, Utrecht, The Netherlands
}

\begin{abstract}
This article qualitatively identifies and explains the barriers that foreign cleantech start-ups can encounter when attempting to enter the Chinese market, as well as the possible strategies that can help overcome these barriers. We base our analysis on interviews with Chinese and foreign entrepreneurs and facilitators. To structure the analysis of such barriers, we use the components of the entrepreneurial ecosystem. We then explain the barriers using institutional theory. We demonstrate that they are caused either by the regulations in China or by the difference between Chinese and Western logics. We further recommend that cleantech entrepreneurs come prepared to China, remain flexible, associate themselves with reputable partners and take advice from those familiar with business in China. Cultural-cognitive barriers might be overcome by integrating the communities of foreign and Chinese start-ups. Regulative barriers can be removed by the Chinese Government, but this conflicts with the logic of state control. Copyright (C) 2015 John Wiley \& Sons, Ltd and ERP Environment
\end{abstract}

Received 5 January 2015; revised 10 April 2015; accepted 14 May 2015

Keywords: China; entry barriers; technology transfer; sustainable entrepreneurship; institutional theory; sustainable development

\section{Introduction}

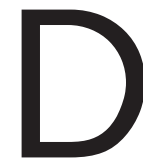

URING THE PAST 30 YEARS, THE CHINESE ECONOMY HAS GROWN ON AVERAGE BY 10\% PER YEAR (IMF, 2013), AND THE urban population has more than tripled from 220 million to 720 million people (World Bank, 20I4a). Over 500 million people have been lifted out of poverty during this period (Montalvo and Ravallion, 20I0; World Bank, 20I4b). However, this progress has incurred great environmental costs. China has seen an enormous increase in greenhouse gas emissions (Guan et al., 20I2), and the country is now responsible for a quarter of the world's $\mathrm{CO}_{2}$ emissions (World Bank, 20I4a). In addition, the country's soil, air and water are seriously polluted (Liu and Diamond, 2005), posing a direct threat to Chinese public health and welfare (Matus et al., 2012). Therefore, the Chinese Government has prioritized solving these environmental problems in its latest five-year plan (Lewis, 20II).

Cleantech, also known as clean technology or environmental technology, can contribute to the sustainable development of China. A common and suitable definition, attributed to the Clean Technology Trade Alliance, states that cleantech is a 'broad base of processes, practices and tools, in any industry that supports a sustainable business

*Correspondence to: Frank J. Van Rijnsoever, Utrecht University, Innovation Studies, Copernicus Institute of Sustainable Development, Utrecht, The Netherlands. E-mail: f.j.vanrijnsoever@uu.nl 
approach, including but not limited to: pollution control, resource reduction and management, end of life strategy, waste reduction, energy efficiency, carbon mitigation and profitability'. ${ }^{\mathrm{I}}$ Even though environmental problems have caused this market to expand rapidly, China's technological knowledge base is still underdeveloped (Fu and Gong, 20II; Liu and Yannan, 20I3), preventing Chinese cleantech firms and entrepreneurs from claiming the market for themselves. This leaves opportunities for start-up cleantech companies from the US and Europe to transfer technologies that can alleviate environmental problems to China (Liu and Yannan, 20I3). In response, a large number of private and public facilitating organizations have been created to support these start-ups (Jolly and Zhu, 20I2). However, despite these efforts, starting operations in the Chinese market is not easy. It has been 30 years since China started to open up its economy (Fenby, 2008) and allow foreign direct investment (Sun, I998). Between 2006 and 2013, around 305 billion dollars were invested in clean energy in China (Climatescope, 20I4). Thereby, China surpassed the USA and the EU as the largest cleantech investor (National Science Board, 20I4). These cleantech investments were mostly dedicated to the development of solar and wind energy (Bloomberg New Energy Finance, 20I5). However, the Chinese Government still sees itself as the primary agent for economic development and thus wants to retain control over its own market (Potter, I995). Many market entry barriers still prevent companies from entering China, and the country is ranked 96th in the 'ease of doing business' ranking (World Bank, 2013).

A substantial number of studies have analyzed market entry into China and identified generic barriers (Barkema et al., I996; Young and Lan, I997; Guillén, 2002; Gielens and Dekimpe, 2007; Amiti and Javorcik, 2008; Johnson and Tellis, 2008; Guerin, 2009; Niu et al., 20I2), such as cultural and economic distance, country risk and openness (see Johnson and Tellis, 2008), trade costs (Amiti and Javorcik, 2008), understanding the market (Niu et al., 20I2) and problems originating from the government (Young and Lan, I997).

Despite these efforts, a comprehensive understanding of the barriers and potential strategies specifically for cleantech start-ups is still lacking. It is important to have such an inventory, as start-ups are different from established companies. Start-ups have a stronger focus on generating product innovation (Ries, 20II) and greater dependency on sales from innovative products (Criscuolo et al., 20I2), and they play an important role in exploring new technology markets (Almeida and Kogut, I997). Compared with established organizations, start-ups have a much smaller resource base and they often lack the resources required to develop and market radical innovations successfully (Vohora et al., 2004; Bruton et al., 20I0). These differences imply that the barriers for start-ups entering the Chinese market differ from the barriers for established companies. This notion is supported by the scarce empirical evidence available, which confirms that smaller firms have a larger chance of successful entry into China than large firms (Johnson and Tellis, 2008), but that many barriers still apply. Additional barriers are associated with the cleantech market (Guerin, 2009). Success in the cleantech market strongly depends on government collaboration (Harris, 20I4), which poses an additional challenge in China.

This article qualitatively identifies and explains the barriers that foreign cleantech start-ups experience when entering the Chinese market, as well as possible strategies that can help to overcome these barriers. Our data come from on-site interviews with Chinese entrepreneurs and facilitators and from business meetings and seminars.

As we are studying a form of sustainable entrepreneurship (Schaltegger and Wagner, 20II), we structure our data analysis and findings using components of the entrepreneurial ecosystem (Spilling, 1996; Neck et al., 2004; Cohen, 2006; Qian et al., 2013), which can be defined as 'the set of tangible and intangible environmental factors that shape the performance of Micro, Small and Medium Enterprises (MSMEs), or start-ups, in a geographically and politically defined area' (Van Weele et al., 20I4). The components of the entrepreneurial ecosystem that we use as points of departure are the government, networks, community, universities, supportive culture, talent pool, market, capital services, legitimacy and supporting services. We apply the entrepreneurial ecosystems approach, because it can capture all of the environmental factors that explain the success or failure rates of foreign start-ups in China. We keep an open view and adapt the framework to the Chinese context where necessary. This leads us to reconceptualize some of the components.

To explain the causes of the barriers, we rely on institutional theory (DiMaggio and Powell, I983; Scott, I995), which has proven to be fruitful in explaining barriers to environmental entrepreneurship and innovation (Smink et al., 20I5). Institutions are informally defined as 'the rules of the game' (North, I990), and they direct the behavior

${ }^{\mathrm{I}}$ Even though this definition of cleantech is often used and attributed to the Clean Technology Trade Alliance in documents, we could not find the definition in its official online material. However, the definition itself is sound and appropriate. 
of agents in society. The barriers that we identify largely stem from 'how things are done', and institutions are the cause of this. We therefore classify the barriers along the three institutional pillars that Scott (I995) identified as origins of institutions: the regulative pillar, the normative pillar and the cultural-cognitive pillar. Institutions in the regulative pillar stem from formal rules and laws. As such, the legitimacy of these institutions is found in legal sanctions. The normative pillar contains social obligations and expectations, such as norms and values. The legitimacy of the institutions in this pillar is of a moral nature. Institutions in the cultural-cognitive pillar largely have historical roots; they are based on common beliefs, 'taken-for-grantedness' and shared understandings of how things are done. Actions that are comprehensible, recognizable and culturally supported are seen as legitimate. By identifying the causes of the barriers, we can indicate which barriers can be most easily removed. This is because regulative barriers are generally more easily solved than those that stem from the other pillars (Scott, I995).

Our theories and results can help researchers and practitioners to understand the difficulties of cleantech technology transfer to China by start-ups and, consequently, the inhibitors of sustainable development. Further, the results of this paper can be seen as help for entrepreneurs who are contemplating entering the Chinese cleantech market. Finally, our analysis aids stakeholders in China and in Western countries who wish to strengthen the cleantech entrepreneurial ecosystem for foreigners.

\section{Methods}

\section{Research Design}

We conducted a qualitative case study to gain an in-depth understanding of the subject matter (see Bryman, 20I3). The lead author spent 4.5 months in China, while the two co-authors joined the lead author for periods of $3-5$ days to assist in data collection, to discuss and interpret the findings and to adjust the data collection where necessary. This ensured an open view, which is typical of qualitative research (see Bryman, 2013).

\section{Data Sources and Sample}

Data were collected in several Chinese regions by conducting 43 semi-structured interviews and by attending five business meetings and five seminars related to building businesses in China. The interviews formed our main source of data, while the other data sources enabled us to verify and add to the findings of these interviews, thus increasing their validity. The majority of the data was collected in Shanghai (32), China's business capital. In addition, interviews and meetings took place in Beijing (6), Shenzhen (4), Suzhou (3), Yixin (2), Changzhou (I) and the Special Administrative Region of Hong Kong (5) to verify whether our findings can be transferred to other Chinese regions and to seek potential new insights. Apart from Hong Kong, the findings were in line with the data from Shanghai, which suggests that we reached theoretical saturation over a large area, the east of China. The number of interviews is well above the recommended minimum sample size of between 15 and 25 for qualitative research (Suddaby, 2006; Mason, 2010).

The sample of interviewees consisted of both Chinese (I5, including Hong Kong) and non-Chinese (28) respondents. The interviewees were entrepreneurs (I9), investors (3) and facilitators of entrepreneurship or technology transfer (2I). The number of interviews with investors seems low, but this perspective was augmented by entrepreneurs and facilitators, who were also able to inform us about this topic. Moreover, eight facilitators also acted as investors as part of their job description. The sources did not contradict themselves and no new topics emerged in this context after finishing our interviews.

The business meeting participants were all Chinese. The seminars had a mix of Chinese and foreign speakers and guests. The Chinese speakers were able to give valuable insights into their perspective and experience in building a business in China and the way in which they deal with certain barriers. The non-Chinese perspective was important to identify the additional barriers that foreigners face when they develop their businesses in China. Entrepreneurs could speak directly from their own experience and the other actors from their experience of advising and helping many entrepreneurs, including entrepreneurs who failed in China. Eleven interviewees and five 
participants in the business meetings operated in a wide range of cleantech industries, from wind turbines to LED lighting to water treatment. This provided a broad view of the barriers encountered by different types of cleantech company. The remaining interviewees and seminar speakers operated in a variety of mostly technology-related industries. Our sample was broader than cleantech alone, as many of the barriers are applicable to foreign start-ups in general.

For the interviews, we relied on purposive sampling (Bryman, 20I3). Potential interviewees were identified through events, desk research and existing contacts. Snowball sampling was performed, as the interviewees were asked to suggest interesting actors to approach for this research. The non-representative sample to which this strategy leads is not problematic, since our aim is only to identify barriers and strategies qualitatively without measuring their importance.

The lead author was allowed to attend business meetings between Western cleantech representatives and Chinese tech-park managers, who discussed the possibilities for cooperation in bringing Western cleantech companies to China. In these meetings, the barriers and possible support were discussed. In addition, the researchers experienced business meetings and the associated cultural barriers first hand and gained more insights specific to cleantech.

\section{Data Collection}

The interview data were collected using a semi-structured interview scheme that was based on the literature. We asked open-ended questions and, if necessary, probing questions to let the interviewees explain and clarify their answers. At the start of each interview, the research goals were introduced to the interviewee, anonymity was assured and the interviewee was asked for permission to use his or her input in this research. The interviews were roughly structured as follows:

- an introduction to the interviewees and their organization;

- questions about the entrepreneurial ecosystem;

- questions about the barriers to building a business in China;

- questions about the resources and support offered to start-ups.

Where possible, and with the interviewee's consent, the interview was recorded and later transcribed. In some interviews, it was impossible or inappropriate to record the conversation; in these cases, elaborate notes were taken. On three occasions, Skype was used because meeting in person was impractical. On six occasions, a translator was used. Interviews were held until no new concepts emerged.

At the business meetings and seminars, the researcher was primarily an observer and on occasion asked questions for clarification. It was either not allowed or impractical to record these meetings, so the researcher again took elaborate field notes.

\section{Analysis}

The interview transcripts and notes were analyzed using the qualitative data analysis program NVivo. During the initial phase of coding, we interpreted the codes in terms of the concepts from the theoretical framework. At the same time, we were open to new codes and concepts, in line with the approach of Glaser and Strauss (ig67) to qualitative data analysis. Next, we categorized the codes, related them to each other and focused on understanding the core concepts of this research: the components of the entrepreneurial ecosystem, the associated barriers for entrepreneurs, the institutional pillars that explain their cause and the possible strategies and support needed to overcome those barriers. During the analysis process, the coding scheme was iteratively discussed between the authors and adapted. The identification of the components of the entrepreneurial ecosystem was straightforward, as the codes for this naturally followed on from the interview scheme. The barriers were then classified per component. In line with our inductive approach, we merged or expanded some of the components of the entrepreneurial ecosystem to improve the fit with the barriers. When this was the case, we explicitly mention it in our results. Furthermore, we classified each barrier by institutional pillar. These were more abstract than the components of the entrepreneurial ecosystem. We used the indicators provided by Scott (1995, p. 5I). In the case of laws, rules or 
sanctions, a barrier was interpreted as regulative. In the case of social norms, values or comparisons, it was seen as normative. In the case of common beliefs, shared logics and mimicking behavior, it was classified as culturalcognitive. We kept an open view and looked for other possible indicators that could provide evidence for a pillar. We found that if evidence for the regulative or normative pillars was lacking, the barrier could be attributed to the cultural-cognitive pillar, which is arguably the broadest and least concrete pillar of the three. It is also possible for a barrier to be classified under two pillars. Finally, the strategies were directly distilled from our data.

\section{Results}

For each component, we discuss its role in the ecosystem, the situation in the Chinese context, the barriers that follow this and the strategies that start-ups can use to overcome those barriers. Table I presents a summary of our results. The first column shows the components from the entrepreneurial ecosystem that fitted our data, the second column the associated barriers and the third column the strategies mentioned. The next column shows our interpretation of the underlying cause of the barriers in terms of the institutional pillars. The final four columns indicate whether these barriers and strategies were mentioned by the Chinese and/or foreign respondents or by entrepreneurs and/or facilitators. It should be noted that some of the perceived barriers and strategies might conflict with Western practices, norms and values. However, we emphasize that our empirical findings stem from the Chinese context, which is substantially different from that of Europe or the US. In our discussion of the results, we rely on example quotes given by respondents to make the topic more tangible. We note that this 'anecdotal evidence' is mostly supported by multiple respondents in our sample. The final four columns in Table I serve as evidence for this. We add that for qualitative research the fact that information is observed is far more important than how often it is observed (Bryman, 2013).

\section{Government}

The government's role in the entrepreneurial ecosystem is to provide regulations for entrepreneurship and possibly additional resources (Gnyawali and Fogel, 1994; Fogel, 200I; Goetz and Freshwater, 2001; Turok, 2005; Roxas et al., 2007). China has a large but fragmented government that consists of many departments, layers and regional divisions. Although improvements are being made, the Chinese judicial system is still seen as weak and corruption is not uncommon (Ramirez, 20I4). A foreign entrepreneur summarized this as follows: 'A lot of the regulatory bodies are not really harmonized with each other. In fact, they compete with each other for power. So you have to please them all'. However, strong government actions against corruption are said to improve the judicial situation and to reduce corruption.

Regarding cleantech, the national government acknowledges environmental problems, and it emphasizes reducing fossil fuel consumption and supporting cleantech R\&D (Lewis, 20II). Three of the seven 'new strategic and emerging markets for 20II-20I5' in the latest five-year plan are cleantech related ${ }^{2}$ (Yao, 20I2). However, these ambitions are not always directly translated into policies in lower government layers. Dealing with the government is one of the barriers most frequently mentioned by entrepreneurs. We categorize the barriers and solutions as follows.

- Visa problems. Foreign entrepreneurs and personnel need visas to reside and work in the country. Since entrepreneurs cannot always obtain working visas, tourist and student visas are often used as alternatives. However, foreign interviewees state that visas are becoming increasingly difficult to obtain and to renew for longer periods of time. This barrier stems from the regulative pillar. Hiring an advisor is a strategy to alleviate these problems, but even then it remains a troublesome process.

- Registration difficulties. Registering a company is the next barrier. 'You have to go to I5 different departments and officers and things. And it takes three to five months to actually open a company' (foreign entrepreneur). Moreover, the entrepreneur is required to invest a certain amount of money in the company, depending on the industry

${ }^{2}$ New energy industry, new energy auto industry, energy-saving and environmental protection industry. 


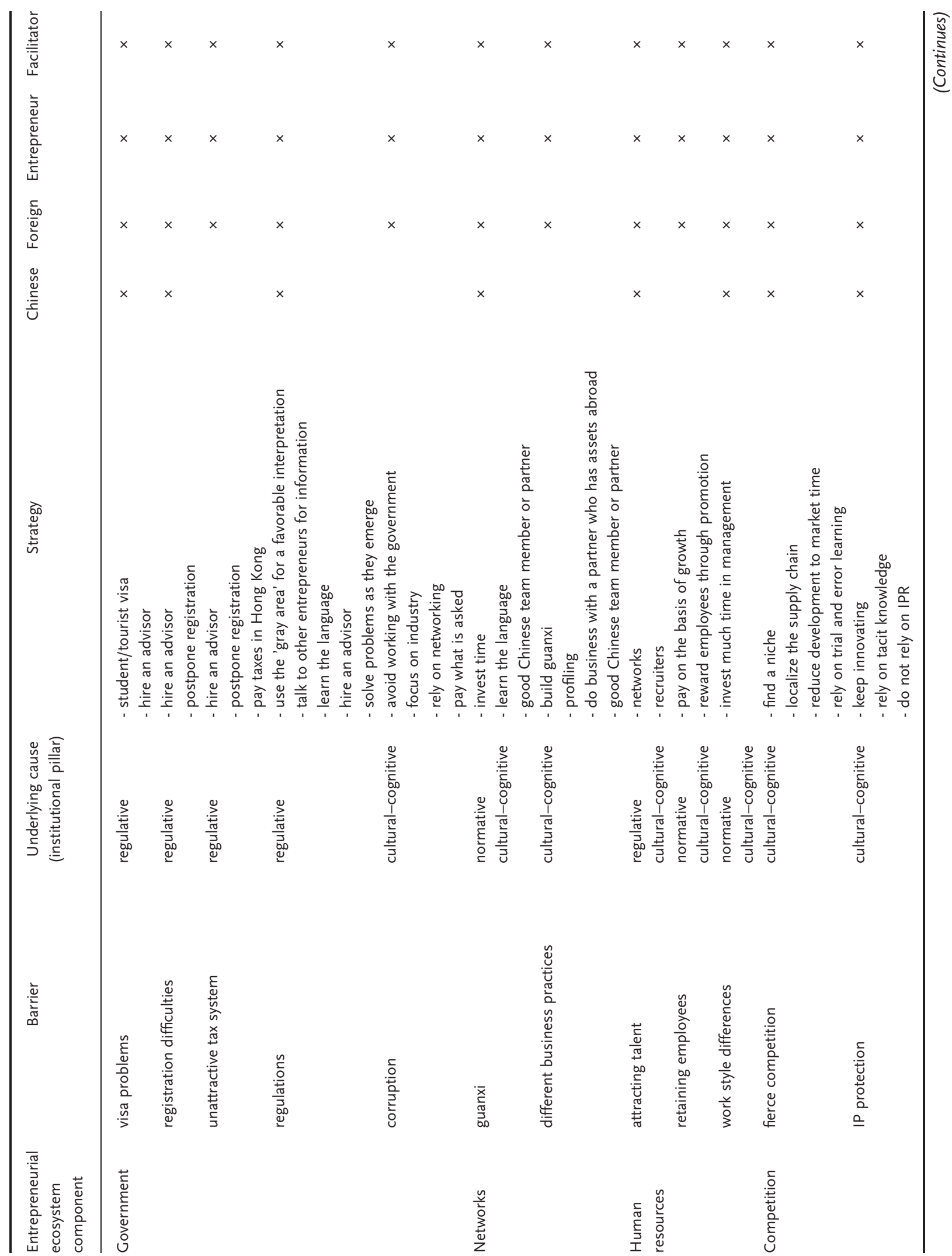




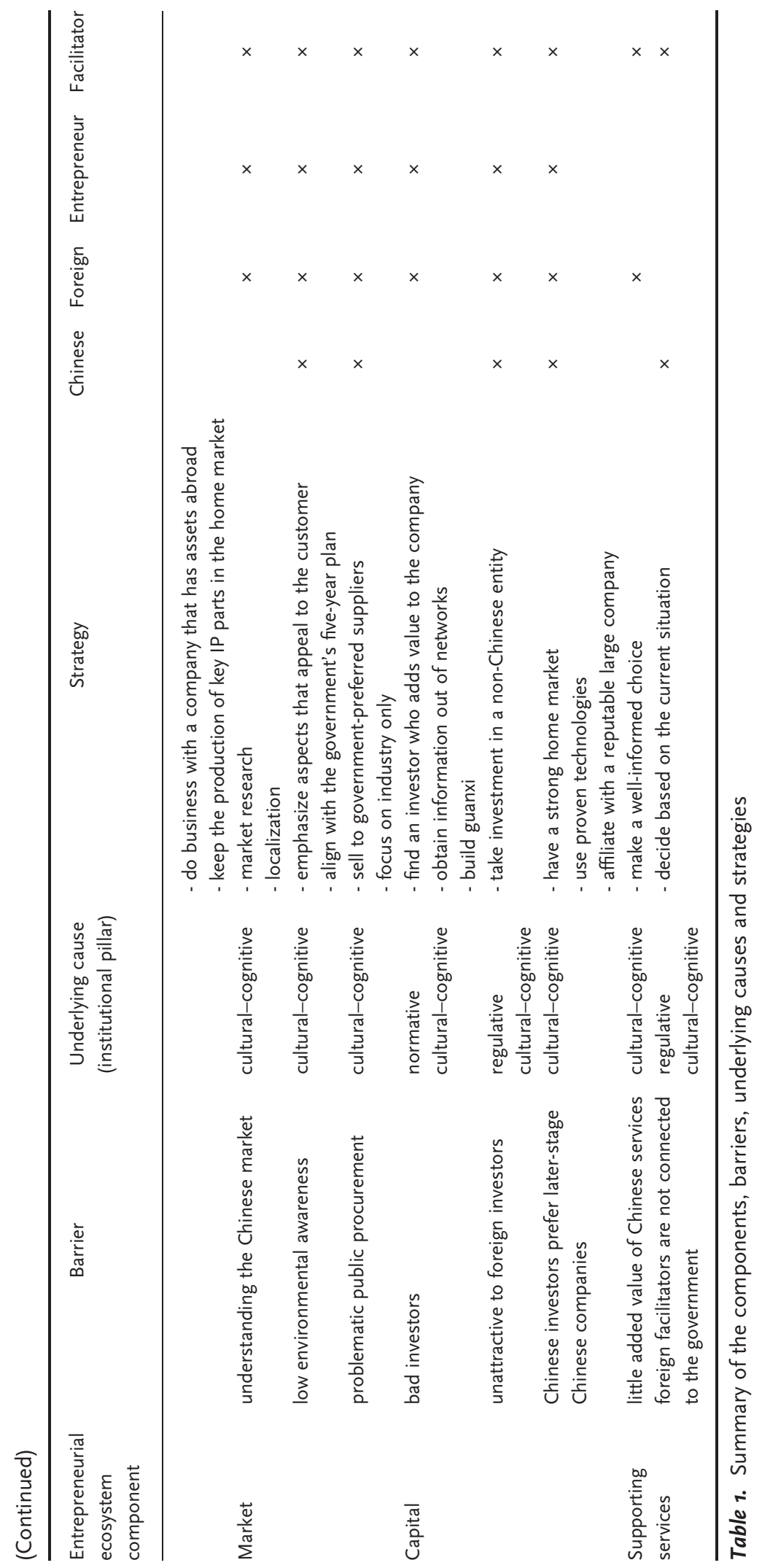


in which it registers. That investment also means a risk, since that money cannot be taken out in an unforeseen dissolution of the company. This barrier also comes from the regulative pillar. Some foreign entrepreneurs say that hiring an advisor is an expensive but worthwhile strategy. The advisor's experience with the process can save the entrepreneur time and frustration. An alternative strategy mentioned by the majority of the entrepreneurs is just to start the business and only deal with the government when it is absolutely necessary: 'When you are very small, you should not start to bother with that otherwise you can spend hours on meeting the administrative staff (foreign entrepreneur). This means postponing registration as long as possible. Even though this practice is often mentioned, it should be noted that it is technically illegal and thus exposes the company to additional risks. This is especially true for firms that deal with the government, such as cleantech firms.

- Unattractive tax system. Taxes are seen as high and complicated. This barrier belongs to the regulative pillar. Foreign entrepreneurs say that hiring an advisor is a strategy to deal with the complicated tax scheme, but taxes remain high. An alternative for small firms is not to register and thus avoid paying taxes altogether, but this might not be advisable for firms that deal with the government frequently. If possible, entrepreneurs structure their money flow in such a way that it is taxed not in mainland China, but in more attractive places, such as Hong Kong.

- Regulatory issues. Regulations in general (which obviously belong to the regulative pillar) are seen by all the respondents as extensive, unclear, incomplete, conflicting and frequently subject to change. This sometimes creates a 'gray area' that companies can use to make a favorable interpretation of the rules. Entrepreneurs can also solve the problem concerning the lack of information on regulations by talking to other experienced entrepreneurs or by seeking support from advisors. However, entrepreneurs discover most through learning by doing: 'Rather than anticipating problems, you just wait for them to happen and once they happen, then you are in firefighting mode. To me, it's very much like the wild west going on' (foreign entrepreneur).

- Corruption. Government corruption is being reduced, but it is still a problem according to foreign entrepreneurs. This is especially the case in the less developed regions of Western China. The cause of corruption is difficult to pinpoint. It is partly due to a lack of regulation or strong norms. This gives rise to opportunistic behavior that has become shared among government officials. Therefore, it is primarily a cultural-cognitive phenomenon. The strategies for dealing with corruption include avoiding working with the government as much as possible. Instead, firms could focus on working with industry, which is perceived to be less corrupt. Entrepreneurs are also advised to rely on networking, which is very important in China (see the next section). Finally, they can just give what is asked from them. It should be noted here that it is often difficult to determine the difference between corruption and appropriate gift giving, due to unclear regulations and cultural differences.

\section{Networking}

According to the literature, actors in the entrepreneurial ecosystem should be well connected through formal and informal networks that facilitate the flow of resources between them (Carlsson and Stankiewicz, I991; Neck et al., 2004; Cohen, 2006). Informal networking is crucial for a successful business in China. Moreover, the processes of business and networking are different from those in Western countries, leading to additional barriers for Western entrepreneurs. Therefore, this part focuses on the process of establishing networks and firms that are sufficiently embedded in the Chinese culture and community. As such, we expand upon the original conceptualization of networks in the entrepreneurial ecosystem literature.

The weak judicial system has contributed to the Chinese way of doing business known as 'guanxi,' which is based on informal networks, relationships, respect and trust (Hills and Man, I998; Yau et al., 2000; Wang, 2007). In theoretical terms, this means that start-ups have to invest in building up social capital as a key resource (Coleman, I988; Adler and Kwon, 2002). Building guanxi is an extensive process of establishing and maintaining relationships. It requires patience, an understanding of indirect communication and usually dinners, (alcoholic) drinks and gifts. Guanxi can also aid in gaining the cooperation of key actors within the government or other crucial stakeholders. Because of the anti-corruption regulation and the more international character of business in China, guanxi might become less important in the future. We identify two barriers in this component.

- Guanxi. Building guanxi is often perceived by foreign interviewees as hard and time consuming, but a necessary investment. A consequence is that events might not happen as quickly as anticipated. The need to build guanxi is 
based on norms and values that have arisen in the absence of strong regulations. Moreover, it contains many traditional and cultural elements that are based on a shared logic. Therefore, this barrier stems from both the normative and the cultural-cognitive pillar. According to foreign entrepreneurs, being a foreigner in China is no longer special, particularly in the business hubs in the east and south of China. Foreigners who speak Mandarin, however, still stand out; they receive more respect and are more favorable business partners for their Chinese counterparts. Therefore, learning the language is an advisable strategy. However, learning the language requires time, which makes it a luxury that many start-ups cannot afford. A reliable Chinese partner or team member is also said to be important for successful formal and informal networking in China, as he or she will be able to understand the indirect communication that is often used.

- Different business practices. Foreign interviewees state that Chinese business practices are complicated and different from those to which they are accustomed. Personal bonds and agreements appear to be worth more than contracts. The latter are often seen more as guidelines for cooperation. 'A contract is seen as something temporary; if the circumstances change and the agreements are no longer beneficial, chances are they don't keep to the contract', says a foreign facilitator. In the absence of strong regulations and norms, these business practices are most strongly associated with the cultural-cognitive pillar. Building guanxi is a very important strategy in this context, because it builds trust. Moreover, time needs to be invested to assess whether the potential business partner can be trusted: 'Profiling is important: try to know who you're dealing with... can you be sure you get the money etcetera' (foreign entrepreneur). This can be achieved by relying on the advice of others in the entrepreneurial community who have dealt with a partner or by following the advice of a Chinese team member. One can also choose to collaborate with partners who are used to dealing with foreign partners or who have assets abroad.

An important issue that is often associated with networks is the existence of an informal start-up community (Feld, 20I2). These communities are based on shared norms, values, practices and trust. They allow entrepreneurs to learn from each other, exchange resources and gain a sense of belonging (Van Weele et al., 20I4). However, the researchers noticed that the communities of foreign start-ups and Chinese start-ups were quite distinct and little interaction took place. This can be explained by the fact that the needs of the two types of start-up differ, but also by the differences that stem from the cultural-cognitive pillar.

\section{Human Resources}

We found that the components university, supportive culture and talent pool of the entrepreneurial ecosystem have similar and related barriers. We categorize these as human resource barriers and we discuss them together.

The role of universities in the entrepreneurial ecosystem is to supply knowledge that can be used by start-ups and to deliver talented graduates who serve as a talent pool for start-ups. We focus on the latter, because technological and scientific knowledge are already present in the start-up. Universities can also contribute to a supportive culture for entrepreneurship. A supportive culture encourages and rewards start-ups for thinking creatively, taking risks and behaving opportunistically (Busenitz et al., 2000; Dickson and Weaver, 2008). Both Chinese and foreign entrepreneurs and facilitators say that the traditional career path in China starts with studying hard. This enables graduates to obtain a job with the government, which means a secure future. The respondents also note that a mindset change has occurred among the younger generation: young people have become more open to alternative career paths and entrepreneurship. The talent pool of new entrepreneurs and talented employees is thus growing. However, a number of barriers are present.

- Attracting talent. Finding talent is the number one management challenge for Chinese and foreign companies in China (Fernandez et al., 20I3). In the interviews, foreign entrepreneurs state that they struggle to find good staff because they do not know where to look, résumés are hard to judge and the overall quality of the candidates is low. McKinsey reported that fewer than Io\% of Chinese job candidates would be suitable for work in a foreign company (Farrell and Grant, 2005). Important reasons for this are the bias towards theory in the education system, language skills and cultural fit. The teaching method is not seen to lead to creative or critical thinking: 'The Chinese education system brings forth very bright students, but it does not lead to good innovative employees. They are clever, but they never open their mouth to share it' (foreign entrepreneur). This barrier has origins in all three pillars. The organization of the education system is largely regulative, as is the absence of good standards. 
However, the difference in culture and thinking is mostly cultural-cognitive. It is a mismatch between how Westerners view talent and how the Chinese system views talent. Foreign interviewees mention two strategies to find good employees: through formal or informal networks and with the help of recruiters. It has to be noted that not all of the interviewees who had used recruiters are satisfied, since the quality of recruitment services differs.

- Retaining employees. A second major human resource barrier is retaining high-quality employees. Some foreign interviewees feel that staff are often not loyal and are likely to leave for a slightly higher salary elsewhere. This is partly refuted by an entrepreneur specializing in recruitment and a survey by Hays Recruiting (20I2), but it is still a potential risk if the employer does not have the right retention strategies. 'Lack of career progression' and 'seeking a new challenge' are more important reasons to leave (Hays Recruiting, 20I2). These barriers are largely driven by logics that stem from the individual employee and the mindset associated with working for a start-up, which differs from the traditional career path. Therefore, this is largely a cultural-cognitive barrier. However, it could be argued that normative elements are associated with this barrier as well, as there are strong social norms in China regarding career progress that stem from traditional values (Leung et al., 20II). As an entrepreneur specializing in recruitment says, 'You have to think differently about how you promote people and how you deal with titles and pay rises on the basis of growth'.

- Work style differences. The work style is also different from the one familiar to Western entrepreneurs. 'People have a "don't look up" mentality. They don't take ownership or initiative. They will never do something that was not asked, because they are afraid of doing something wrong', says a Chinese entrepreneur who has lived in the West for most of his life. The fear of failure has clear normative roots, as employees want to avoid the negative social implications of making an error. However, it has evolved into a shared logic that also forms part of the cultural-cognitive pillar. Moreover, this shared logic is not only attributed to the Chinese; it also results from the mismatch concerning Western entrepreneurs' expectations of their personnel. According to foreign interviewees, they need to invest considerably more management time to achieve the same value from their Chinese staff. For start-ups, however, this investment is much more difficult to make than for large companies.

\section{Competition}

The entrepreneurial ecosystem literature emphasizes the market as an important component. However, it focuses mostly on the demand side of the market and less on competition between suppliers of technologies. Competitors can be incumbents or other new entries that target the same market segment. They can be firms that have discovered opportunities independent of one another or followers that copy a product. Both Chinese and foreign interviewees state that the Chinese competition is very fierce. Therefore, companies need a distinct competitive edge to stay ahead of their competitors and survive. However, some foreign entrepreneurs in China are not particularly concerned with competition since the market is large enough for companies to co-exist. Most entrepreneurial and cleantech activities take place in the most developed 'first-tier' cities, such as Shanghai and Beijing. As such, the competition between high-tech firms in these regions is the strongest. Less developed regions, on the other hand, are less competitive and more in need of environmental innovation. However, the solutions needed there are lower tech and these regions are generally less accessible for foreigners. The following barriers were identified.

- Fierce competition. Competitors move fast; they enter markets rapidly and make unpredictable moves. 'The competitors here may come up with something that you cannot even imagine, because it's outside of your knowledge' (foreign facilitator). This barrier is based on a shared market logic of action that one has to move fast to exploit opportunities, which makes it part of the cultural-cognitive pillar. The fierce competition explains why many foreign entrepreneurs say they would prefer not to compete with the Chinese in the same market, but rather to find a niche. The strategies mentioned to stay competitive include localizing the supply chain to reduce costs, reducing the development to market time, learning from early trials of the product/service in the market and continuing to innovate to stay ahead of the competition.

- IP protection. IP (intellectual property) protection is also an often-mentioned barrier. Although the regulation and enforcement of IP rights (IPRs) are improving, many interviewees still see them as an issue. 'The Chinese are good at copying' (foreign entrepreneur) and IP is difficult to protect. This is especially a problem for 
IP-intensive industries, such as cleantech. IP infringement is the result of the lack of IP regulations that are enforced or norms against copying. This has resulted in the logic that copying is allowed, as there are no sanctions against it, which places it in the cultural-cognitive pillar. This logic conflicts with the Western system of IP protection. Foreign entrepreneurs and facilitators do not recommend that any company should rely on IP. Instead, companies should keep innovating their product or service and rely on tacit knowledge that is difficult to imitate to stay ahead of the competition. Possible strategies to protect IP include engaging in business with a company that has assets abroad, where there is a stronger rule of law, and making it difficult to duplicate technology, for instance by keeping the production of key IP parts in the home market and only shifting the production of the less IP-sensitive parts to China. On the other hand, being copied can also be seen as a good sign because 'it validates the idea', a foreign entrepreneur states. As such, it gives legitimacy to the company and the technology, which increases its chances of survival (Hekkert et al., 2007). As long as the market is large enough, IP infringement is not an immediate problem, as companies can co-exist.

\section{Market}

The market comprises the firms, consumers or governmental agencies that purchase the start-up's products or services. Understanding the market is often seen as key to start-up success (Ries, 20II; Blank, 20I3). Research has shown that this is one of the most difficult challenges in China (Niu et al., 20I2). The Chinese market, including the cleantech market, is seen as fragmented, with differences between regions and levels of development.

- Understanding the Chinese market. The Chinese market is unique and difficult to understand, according to foreign entrepreneurs and facilitators: 'Anything you do in China is almost like just for China because the market is so unique and the whole environment and all the pieces are so different' (foreign entrepreneur). This barrier is mostly the result of a shared understanding between foreigners. It is part of the cultural-cognitive pillar. Foreign interviewees state that the tailoring of products, services and marketing to regional Chinese demands and thorough market research by a local agent are crucial for the success of foreign companies in China.

- Low environmental awareness. Although the government acknowledges the environmental issues in China, one of the main barriers to cleantech mentioned is that Chinese customers are perceived to have a low level of environmental awareness. Earlier studies have confirmed that Chinese people generally have low environmental attitudes (Xu et al., 2013; Hui and Zhang, 2015) and little knowledge of environmental risks (Zhang et al., 20I3) and that there is little pressure from Chinese customers on the environmental strategies of firms (Wu, 20I5). 'Water and energy are too cheap here to be a problem', says a foreign cleantech entrepreneur. 'Saving maintenance cost and energy, I don't even mention that anymore, they don't care about it. They want stuff that is visible.' Chinese customers generally seem to find other aspects of products more important than their environmental impact. Moreover, Chinese customers are seen to have short-term vision, as a foreign entrepreneur explains: 'It is hard to sell big solutions in China; they always go for the small and easy fix'. These different preferences are again most likely the result of shared logics that conflict with those of Western cleantech entrepreneurs. Therefore, it is part of the cultural-cognitive pillar. We found no evidence that the other pillars play a role here. One strategy in marketing is to emphasize the aspects of a product that yield immediate and visible benefits. Moreover, according to different interviewees, opportunities arise when industry has to meet certain regulations for which it needs clean technologies. Technologies that are likely to have a large market are those that are aligned with the government's five-year plan.

- Problematic public procurement. Industry and government are big potential clients for cleantech companies. However, selling to the government is not always easy. A Chinese facilitator describes the governmental procurement processes as follows: 'Selling to the government is impossible because it always buys from the same supplier, regardless of the price or quality. It is not a free market'. This barrier is not the result of regulations or social norms. The quote illustrates that the logic is always to buy from the same supplier, which makes it part of the cultural-cognitive pillar. Again, this conflicts with the Western system, in which there are often strong regulations about public procurement. As a strategy, the same facilitator recommends that 'the only way is to sell to the government suppliers, who will sell it to the state-controlled companies'. Another strategy is to focus on industry as the only client. 


\section{Capital}

Capital services are important in the entrepreneurial ecosystem as they invest the required financial resources in start-ups. This is especially true for cleantech innovation in small firms (Halme and Korpela, 20I4), but such funding is hard to obtain in Europe and the US (Randjelovic et al., 2003). However, in line with governmental ambitions, China is known as the world's largest commercial cleantech investor (Bloomberg New Energy Finance, 2013). The interviewees agree that capital is available for cleantech, but they note that finding good investors and attracting financial resources are not easy because of three main barriers.

- Bad investors. It has become more popular among the new rich in China to invest in start-ups; however, foreign start-ups claim that these investors are often inexperienced and have unrealistic expectations and their interests are not always in line with the companies' best interests. As a result, foreign entrepreneurs and facilitators say that there are many bad investors who inflict more harm than good on start-ups. For example, one interviewee was expected to hire a family member of his investor. Others told stories of investors demanding $90 \%$ of the shares for a relatively small investment, because money is seen as much more valuable than an idea or a company. This barrier is primarily the result of a difference in logics between Chinese investors and Western entrepreneurs when it comes to the value of different resources and the role that investors play. It is part of the cultural-cognitive pillar. Interviewees also mention that being an investor is fashionable among newer wealthy Chinese people, which adds a normative element. Foreign entrepreneurs and facilitators say that the strategy here is to find (scarce) investors who add value to the company in the form of a network and/or knowledge next to a reasonable financial investment. This can be achieved by using information from formal and informal networks and by becoming acquainted with the real intentions of the investors during the process of building guanxi.

- Unattractive to foreign investors. Chinese laws make it very difficult to take money invested or earned in China out of the country. Therefore, foreign investors are concerned that they will not be able to have their investment back. This barrier is a clear example of the regulative pillar, but it also contains a cultural-cognitive element, as this purposeful legislation (i.e. keeping money in the country) conflicts with the view of foreign investors. A common strategy mentioned by foreign interviewees is to place investments in a non-Chinese mainland entity of the company, such as a holding company in Hong Kong. Conducting business in Hong Kong is easier than on the mainland, according to entrepreneurs and facilitators in Hong Kong. Setting up and closing a business in Hong Kong is inexpensive, easy and quick; there is a strong rule of law that resolves most issues around the violation of contracts and IP infringements, and there are fewer cultural and language barriers because Hong Kong is more international and English is an official language.

- Chinese investors prefer later-stage Chinese companies. Although foreign technology generally has a good reputation, foreign early-stage companies still have to gain the credibility, trust and social capital required for Chinese investors to place an investment. Chinese investors prefer to invest in Chinese companies or later-stage companies with a proven technology and market abroad. A Chinese investor in cleantech says 'Later stage is better. You should have at least formed a team, with a Chinese who understands the Chinese market'. The reluctance to invest in foreign start-ups is understandable, since the many barriers described above make such a move a risky endeavor. This barrier is based on a shared understanding and common beliefs, which make it part of the cultural-cognitive pillar. To reduce the risks and to become a more attractive partner, it helps already to have a strong home market, a proven technology or a clear affiliation with a reputable foreign or Chinese partner.

\section{Supporting Services}

Professional supporting services provide the knowledge and skills that a start-up does not have in-house or chooses to outsource. They can alleviate some of the barriers posed by the entrepreneurial ecosystem. Because many foreign companies see the potential of China and want to explore the possibilities, many businesses and foreign governments offer supporting services for foreign companies in China, such as lawyers, accountants, consultants, consulates and chambers of commerce. The Chinese Government also sees the importance of innovation and entrepreneurship and tries to support them by hosting start-ups in its incubators. We identified two barriers associated with these supporting services. 
- Little added value of Chinese services. Foreign interviewees mention that many government-supported incubators have excellent resources but fail to add real value to their start-ups since they do not have the right expertise and have little interest in the success of the start-ups. One foreign facilitator explains: 'There has got to be Ioo० incubators in China now; it's ridiculous. And they throw tons of money; they won't take equity, because they have zero interest in helping you once they have given you the money'. Although regulations support start-ups, incentives to support the company in terms of other resources, such as business knowledge or social capital, seem to be lacking. The logic of spending the money is in line with the aforementioned observation about how investors value money over ideas, or perhaps more generally, the logic of valuing tangible over intangible resources, which was also observed by Van Weele et al. (2013) among inexperienced European entrepreneurs. It is thus part of the cultural-cognitive pillar. A strategy here is to make a well-informed choice prior to making use of an incubator or support program. Again, the experience of other foreign entrepreneurs in China is helpful here.

- Foreign facilitators are not connected to the government. One advantage that Chinese government incubators generally have over foreign facilitators is a good relationship with the government. This can be quite useful, for instance, when an entrepreneur wants to apply for a grant for one of the government's innovation and research projects, as a Chinese facilitator explains: 'These do not come to you; you have to discover them by yourselves usually. Finding them and doing the application can be time consuming and hard. We have people who focus purely on that; they search for project grants and hear about them through their government contacts. They also have a lot of experience in applying'. In the case of cleantech, a good government relationship can be especially beneficial. The reasons for the underdevelopment of relationships between foreign facilitators and the Chinese Government vary widely, including the aforementioned cultural and language barriers, lack of transparency and different valuations of the need to maintain government relationships (see above). Therefore, this barrier is mostly a culturalcognitive one. However, the opaque organization of the government is regulative. Another novel regulative element is the new anti-corruption laws that prevent the building of relationships with the government that are too intimate. These regulations might give foreign facilitators a somewhat more level playing field in comparison with their Chinese counterparts. There is no apparent strategy for this barrier. Rather, each start-up should decide how to deal with the government based on how important government relationships are.

\section{Conclusion and Implications}

Our first observation is that the barriers have either regulative or cultural-cognitive causes. Normative institutions were observed, but always in conjunction with another pillar. The strategies for start-ups to overcome the barriers fit the two underlying institutional causes. The main strategy is to come well prepared, in terms of resources and time, but also to be well equipped with knowledge about the Chinese society, culture and, if possible, language. Entrepreneurs can anticipate which barriers will be applicable to their situation. However, they always need to be flexible and able to adapt to new circumstances easily and do not need to rely too much on formal static regulations or IP. This latter trait fits with the dynamic nature of start-ups, which arguably make more suitable vessels for technology transfer to China than large companies, which are known to be more inert (Cyert and March, I963; Hannan and Freeman, I984). For start-ups, it is advisable to be associated with a reputable large company that provides the required credibility (Rao et al., 2008; Van Rijnsoever et al., 20I4). Third, it is important to obtain advice or help from people who are more experienced with technology transfer, such as facilitating incubators, consultants and advisors, as well as from other members of the start-up community. Finally, for start-ups that feel less confident about entering China, it might be advisable to explore the easier Hong Kong route or to find a suitable business partner in China who can conduct all the activities there.

Facilitators and Western policy makers can enable a soft landing for cleantech start-ups by teaching them how to deal with the regulative and cultural cognitive barriers. An example is starting specialized incubation programs that pay attention to cultural and language differences. In addition, facilitating matchmaking between start-ups and reputable experienced Western companies or Chinese parties (e.g. reliable investors or facilitators) can aid the transfer to China. Furthermore, Western embassies and consulates can actively aid this process on site. Another useful method is to facilitate a start-up community in which entrepreneurs can learn from each other (Van Weele et al., 20I4). 
Currently foreign and Chinese entrepreneurs operate in different communities, which can be explained by the fact that they have different needs, and there is a mismatch between Western and Chinese logics. Foreign entrepreneurs often lack the knowledge and skills needed to conduct business in the Chinese context, while Chinese entrepreneurs primarily lack a strong technology base. We recommend that facilitators should actively build a start-up community that includes both Chinese and foreign start-ups. This would provide an opportunity to overcome some of the cognitivecultural barriers and mismatches, allowing the two types of start-up to strengthen each other's weaknesses.

The Chinese Government can fix some of the regulative barriers with relative ease. However, the question is whether the Chinese Government is willing to open up the market. It is known that the government has the logic to remain in control of its own domestic market (Potter, I995). Such an underlying cultural-cognitive institution is much more difficult to change than the resulting regulative institutions (Scott, I995), because cultural-cognitive institutions are often deeply embedded in the culture and partly beyond governmental control. However, as the environmental problems in China require immediate action, we urge Chinese policy makers to act in line with their fiveyear plan and to address the regulative barriers as much as possible for the cleantech sector. Specifically, the visa process and the registration of new companies can be addressed with relative ease.

Our paper is an example of how the social sciences can be used to help solve grand societal challenges (Van Langenhove, 20I2; Van Rijnsoever, 20I2). However, we also sound some notes of caution. First, we acknowledge that cleantech is a very broad sector. Accordingly, the opportunities and barriers can be very company specific and not all barriers are applicable to each start-up. Second, we note that our data are based on our qualitative interpretation of the perceptions of entrepreneurs and facilitators. To minimize bias, we worked with multiple researchers, consulted the literature and used additional data sources to triangulate our data. Finally, we acknowledge that we do not have a quantitative comparison that allows us to determine the exact influence of each barrier on successful market entry. This is an avenue for further research.

Overall, the strategies and recommendations given here serve as a little helper for start-ups, but they are no guarantee of success. Those start-ups that succeed in overcoming the barriers can benefit from the huge potential that the Chinese cleantech market has to offer. In return, these start-ups can aid sustainable development in China.

\section{References}

Adler PS, Kwon S-W. 2002. Social capital: prospects for a new concept. Academy of Management Review 27: I7-40.

Almeida P, Kogut B. I997. The exploration of technological diversity and geographic localization in innovation: start-up firms in the semiconductor industry. Small Business Economics 9: 2I-3I.

Amiti M, Javorcik BS. 2008. Trade costs and location of foreign firms in China. Journal of Development Economics 85: I29-I49.

Barkema H, Bell J, Pennings J. I996. Foreign entry, cultural barriers and learning. Strategic Management Journal I7: I5I-I66.

Blank S. 20I3. Why the lean start-up changes everything. Harvard Business Review 9r: 63-72.

Bloomberg New Energy Finance. 20I3. New Investment in Clean Energy Fell II\% in 20I2. London.

Bloomberg New Energy Finance. 2015. Global Trends in Clean Energy Investment: Rebound in Clean Energy Investment in 2014 Beats Expectations. London.

Bruton GD, Ahlstrom D, Li HL. 2oIo. Institutional theory and entrepreneurship: where are we now and where do we need to move in the future? Entrepreneurship: Theory and Practice 34: 42I-440.

Bryman A. 2013. Social Research Methods, 4th edition. Oxford University Press: Oxford.

Busenitz L, Gomez C, Spencer J. 2000. Country institutional profiles: unlocking entrepreneurial phenomena. Academy of Management Journal 43: 994-1003.

Carlsson B, Stankiewicz R. I991. On the nature, function and composition of technological systems. Journal of Evolutionary Economics I: 93-II8.

Climatescope. 20I4. Climatescope 2014: Mapping the Global Frontiers for Clean Energy Investment. Bloomberg New Energy Finance Multilateral Investment Fund, Part of the Inter-American Development Bank, UK Department for International Development, Power Africa: Washington D.C.

Cohen B. 2006. Sustainable valley entrepreneurial ecosystems. Business Strategy and the Environment I5: I-I4.

Coleman JS. I988. Social capital in the creation of human capital. American Journal of Sociology 94: S95-Si20.

Criscuolo P, Nicolaou N, Salter A. 20I2. The elixir (or burden) of youth? Exploring differences in innovation between start-ups and established firms. Research Policy 4I: 319-333.

Cyert RM, March JG. I963. A Behavioral Theory of the Firm: Prentice-Hall International Series in Management. Prentice-Hall: Englewood Cliffs, NJ.

Dickson PH, Weaver KM. 2008. The role of the institutional environment in determining firm orientations towards entrepreneurial behavior. International Entrepreneurship and Management Journal 4: 467-483. 
DiMaggio PJ, Powell WW. I983. The iron cage revisited: institutional isomorphism and collective rationality in organizational fields. American Sociological Review 48: 147-160.

Farrell D, Grant A. 2005. Addressing China's looming talent shortage. McKinsey Quarterly 56: 70-79.

Feld B. 20I2. Startup Communities: Building an Entrepreneurial Ecosystem in your City. Wiley: Hoboken, NJ.

Fenby J. 2008. The Penguin History of Modern China: the Fall and Rise of a Great Power, 1850-2009. Penguin: London.

Fernandez JA, Xu B, Zhou D, Puyuelo MJ, Li J. 2013. Business in China Survey 20I3. CEIBS: Shanghai.

Fogel G. 200I. An analysis of entrepreneurial environment and enterprise development in Hungary. Journal of Small Business Management 39: I03-IO9.

Fu X, Gong Y. 20II. Indigenous and foreign innovation efforts and drivers of technological upgrading: evidence from China. World Development 39: I2I3-I225.

Gielens K, Dekimpe MG. 2007. The entry strategy of retail firms into transition economies. Journal of Marketing 7I: I96-2I2.

Glaser BG, Strauss AL. I967. The Discovery of Grounded Theory: Strategies for Qualitative Research. Aldine: Chicago, IL.

Gnyawali D, Fogel D. I994. Environments for entrepreneurship development: key dimensions and research implications. Entrepreneurship: Theory and Practice 18: 43-62.

Goetz SJ, Freshwater D. 200I. State-level determinants of entrepreneurship and a preliminary measure of entrepreneurial climate. Economic Development Quarterly 15: 58-70.

Guan D, Liu Z, Geng Y, Lindner S, Hubacek K. 20I2. The gigatonne gap in China's carbon dioxide inventories. Nature Climate Change 2: 672-675.

Guerin TF. 2009. An assessment and ranking of barriers to doing environmental business with China. Business Strategy and the Environment I8: $380-396$.

Guillén MF. 2002. Structural inertia, imitation, and foreign expansion: South Korean firms and business groups in China, I987-I995. Academy of Management Journal 45: 509-525.

Halme M, Korpela M. 20I4. Responsible innovation toward sustainable development in small and medium-sized enterprises: a resource perspective. Business Strategy and the Environment 23: 547-566.

Hannan MT, Freeman JH. I984. Structural inertia and organisational change. American Sociological Review 49: I49-164.

Harris PG. 20I4. Climate policy: risk-averse governments. Nature Climate Change 4: 245-246.

Hays Recruiting. 20I2. Retention: Is It Getting Enough Attention? http://www.hays.cn/en/press-releases/HAYS_08825I [8 June 20I5].

Hekkert MP, Suurs RAA, Negro SO, Kuhlmann S, Smits REHM. 2007. Functions of innovation systems: a new approach for analysing technological change. Technological Forecasting and Social Change 74: 4I3-432.

Hills P, Man CS. 1998. Environmental regulation and the industrial sector in China: the role of informal relationships in policy implementation. Business Strategy and the Environment 7: 53-70.

Hui Z, Zhang T. 20I5. A research on the methods and strategies for developing citizens' environmental awareness and advancing citizens' environmental contributive actions. Canadian Social Science II: I29-I35.

IMF. 20I3. World Economic Outlook Database. http://www.imf.org/external/pubs/ft/weo/20I3/or/weodata/weorept.aspx?sy=I980\&ey=20I8\&sort= country\&ds=.\&br=I\&prI. $\mathrm{x}=40 \&$ prI. $y=0 \& \mathrm{c}=924 \& \mathrm{~s}=\mathrm{NGDP} \_$RPCH,PPPPC\&grp $=0 \& \mathrm{a}=[8$ June 2015$]$.

Johnson J, Tellis GJ. 2008. Drivers of success for market entry into China and India. Journal of Marketing 72: I-I3.

Jolly D, Zhu F. 20I2. Chinese S\&T parks: the emergence of a new model. Journal of Business Strategy 33: 4-I3.

Leung SA, Hou Z-J, Gati I, Li X. 20II. Effects of parental expectations and cultural-values orientation on career decision-making difficulties of Chinese University students. Journal of Vocational Behavior 78: II-20.

Lewis J. 20II. Energy and Climate Goals of China's 12th Five-Year Plan. PEW Center on Global Climate. Change: Arlington, VA.

Liu C, Yannan T. 20I3. EU Firms Eye China's Clean-Tech Market. chinadaily.com.cn [8 June 20I5].

Liu J, Diamond J. 2005. China's environment in a globalizing world. Nature 435: II79-II86.

Mason M. 20I0. Sample size and saturation in PhD studies using qualitative interviews. Forum Qualitative Sozialforschung/Forum: Qualitative Social Research II(3): Article 8.

Matus K, Nam K-M, Selin NE, Lamsal LN, Reilly JM, Paltsev S. 20I2. Health damages from air pollution in China. Global Environmental Change 22: $55-66$.

Montalvo JG, Ravallion M. 20I0. The pattern of growth and poverty reduction in China. Journal of Comparative Economics 38: 2-16.

National Science Board. 20I4. Science and Engineering Indicators 2014 (NSB I4-OI). Arlington VA: National Science Foundation.

Neck HMH, Meyer GD, Cohen B, Corbett AC. 2004. An entrepreneurial system view of new venture creation. Journal of Small Business Management 42: 190-208.

Niu Y, Dong LC, Chen R. 20I2. Market entry barriers in China. Journal of Business Research 65: 68-76.

North DC. I990. Institutions, Institutional Change and Economic Performance. Cambridge University Press: Cambridge.

Potter PB. I995. Foreign investment law in the People's Republic of China: dilemmas of state control. China Quarterly I41: I55-I85.

Qian H, Acs ZJ, Stough RR. 20I3. Regional systems of entrepreneurship: the nexus of human capital, knowledge and new firm formation. Journal of Economic Geography I3: 559-587.

Ramirez CD. 20I4. Is corruption in China 'out of control'? A comparison with the US in historical perspective. Journal of Comparative Economics 42: 76-9I.

Randjelovic J, O'Rourke AR, Orsato RJ. 2003. The emergence of green venture capital. Business Strategy and the Environment I2: 240-253.

Rao RS, Chandy RK, Prabhu JC. 2008. The fruits of legitimacy:why some new ventures gain more from innovation than others. Journal of Marketing 72: $58-75$.

Ries E. 20II. The Lean Startup: How Today's Entrepreneurs Use Continuous Innovation to Create Radically Successful Businesses. Random: Portfolio Penguin, London. 
Roxas HB, Lindsay V, Ashill N, Victorio A. 2007. An institutional view of local entrepreneurial climate. Journal of Asia Entrepreneurship and Sustainability 3: I-28.

Schaltegger S, Wagner M. 20II. Sustainable entrepreneurship and sustainability innovation: categories and interactions. Business Strategy and the Environment 20: 222-237.

Scott WR. I995. Institutions and Organizations, 2nd edn, Foundations for Organizational Science. Sage: Thousand Oaks, CA.

Smink MM, Hekkert MP, Negro SO. 20I5. Keeping sustainable innovation on a leash? Exploring incumbents' institutional strategies. Business Strategy and the Environment 24: 86-IOI.

Spilling OR. I996. The entrepreneurial system: on entrepreneurship in the context of a mega-event. Journal of Business Research 36: 9I-I03.

Suddaby R. 2006. From the editors: What grounded theory is not. Academy of Management Journal 49: 633-642.

Sun H. 1998. Macroeconomic impact of direct foreign investment in China: 1979-96. World Economy 21: 675-694.

Turok I. 2005. Cities, competition and competitiveness: identifying new connections. In Changing Cities: Rethinking Urban Competitiveness, Cohesion and Governance, Buck N, Gordon I, Harding A, Turok I (eds). Palgrave Macmillan: New York; $25-43$.

Van Langenhove L. 20I2. Make social sciences relevant. Nature 484: 442.

Van Rijnsoever FJ. 20I2. Sociology: the social sciences are already relevant. Nature 485: 309 .

Van Rijnsoever FJ, Welle L, Bakker S. 20I4. Credibility and legitimacy in policy-driven innovation networks: resource dependencies and expectations in Dutch electric vehicle subsidies. Journal of Technology Transfer 39: 635-66I.

Van Weele MA, van Rijnsoever FJ, Nauta F. 20I3. Take them by the hand? Unconsciously incompetent entrepreneurs and incubation processes. In 35th DRUID celebration conference, Barcelona, June I7th to I9th, 2013.

Van Weele MA, Steinz HJ, Van Rijnsoever FJ. 20I4. Start-ups down under: how start-up communities facilitate Australian entrepreneurship. In DRUID Society conference, Copenhagen, June I6th to I8th, 2014.

Vohora A, Wright M, Lockett A. 2004. Critical junctures in the development of university high-tech spinout companies. Research Policy 33: I47-I75.

Wang CL. 2007. Guanxi vs. relationship marketing: exploring underlying differences. Industrial Marketing Management 36: 8I-86.

World Bank. 20I3. Doing Business 2014: Understanding Regulations for Small and Medium-Size Enterprises Doing Business. World Bank: Washington D.C.

World Bank. 20I4a. World Development Indicators: China. World Bank: Washington D.C.

World Bank. 20I4b. China Overview. http://www.worldbank.org/en/country/china/overview\#I [8 June 20I5]

Wu J. 20I5. Differentiated customer pressures and environmental policies in China. Business Strategy and the Environment 24: I75-I89.

Xu L, Shen J, Marinova D, Guo X, Sun F, Zhu F. 20I3. Changes of public environmental awareness in response to the Taihu blue-green algae bloom incident in China. Environment, Development and Sustainability I5: I28I-1302.

Yao L. 20I2. China releases I2th Five-Year Plan for National Strategic Emerging Industries. China Brief. News. http://www.china-briefing.com/ news/2012/07/25/china-releases-I2th-five-year-plan-for-national-strategic-emerging-industries.html [8 June 20I5].

Yau OHM, Lee JSY, Chow RPM, Sin LYM, Tse ACB. 2000. Relationship marketing the Chinese way. Business Horizons 43: 16-24.

Young S, Lan P. I997. Technology transfer to China through foreign direct investment. Regional Studies 3r: 669-679.

Zhang L, He G, Mol APJ, Lu Y. 2013. Public perceptions of environmental risk in China. Journal of Risk Research I6: I95-209. 